\title{
THE INFLUENCE OF GERMINATION TEMPERATURE AND ULTRA-LOW DOSES OF BENZOTRIAZOLE ON MORPHO-PHYSIOLOGICAL PARAMETERS OF ONIONS OF DIFFERENT SPECIES IN MODEL EXPERIMENTS
}

(C) 2020

\author{
Selezneva Ekaterina Sergeevna, candidate of biological sciences, \\ associate professor of Biochemistry, Biotechnology and Bioengineering Department \\ Gryaznova Maria Olegovna, student of Biology Faculty \\ Samara National Research University (Samara, Russian Federation)
}

Abstract. The adaptation of plants is manifested in the preservation of their physiological functions when exposed to various extreme environmental factors. In model experiments, we examined the influence of the combined action of such factors as alcohol solutions of benzotriazole in low concentrations $(0,00001 ; 0,0001 ; 0,001 \mathrm{mg} / \mathrm{ml})$ and contrasting positive temperatures $\left(+12^{\circ} \mathrm{C}\right.$ and $\left.+22^{\circ} \mathrm{C}\right)$ on germinating ability and growth processes of three species of onions (Allium sulphur, Allium fistulosum and Allium schoenoprasum) differing in various adaptive capabilities. It was found that, regardless of the germination temperature, with an increase in the concentration of benzotriazole solutions in a selected concentration range, stimulation of seed germination is observed for all studied species compared to the control. Benzotriazole had the maximum stimulating effect at a concentration of $0,001 \mathrm{mg} / \mathrm{ml} \mathrm{when}$ germinating seeds at a temperature of $+12^{\circ} \mathrm{C}$. The effect on growth processes was determined by the average length of the roots of onions on the fifth day of growth. It was found that the length of the roots of onions of all studied species when germinating in benzotriazole solutions at a temperature of $+12^{\circ} \mathrm{C}$ does not significantly differ from that in the control. When germinating seeds at $+22^{\circ} \mathrm{C}$, the root length of only two species (Allium cepa, Allium fistulosum) was higher than in the control. Possible mechanisms of the observed phenomenon are discussed.

Keywords: Allium sulphur L.; Allium fistulosum L.; Allium shoenoprasum L.; root length; germinating ability of seeds; survival; contrasting positive temperatures; ecotoxicity; ultra-low doses; benzotriazole; model experiments; xenobiotics; inhibition; stimulation; tolerance; adaptation.

$* * *$

УДК 581.1

DOI 10.24411/2309-4370-2020-11114

Статья поступила в редакцию 25.12.2019

\section{ОЦЕНКА ЭКОЛОГИЧЕСКОГО СОСТОЯНИЯ РЕКРЕАЦИОННЫХ ЗОН Г. НИЖНЕГО НОВГОРОДА ПО УРОВНЯМ ЗАГРЯЗНЕНИЯ ПОЧВ ТЯЖЕЛЫМИ МЕТАЛЛАМИ И БИОИНДИКАЦИОННЫМ ПОКАЗАТЕЛЯМ ЛИСТЬЕВ ВЕTULA PENDULA ROTH}

(C) 2020

Сидоренко Михаил Владимирович, кандидат биологических наук, доцент кафедры экологии

Юнина Валентина Петровна, старший преподаватель кафедры экологии

Ерофеева Елена Александровна, доктор биологических наук, доцент кафедры экологии

Савинов Александр Борисович, кандидат биологических наук, доцент кафедры экологии

Кузнецов Максим Дмитриевич, аспирант кафедры экологии

Новожилов Денис Алексеевич, аспирант кафедры экологии

Национальный исследовательский Нижегородский государственный университет им. Н.И. Лобачевского

(2. Нижний Новгород, Российская Федерация)

Аннотация. В данной работе проводилась оценка экологического состояния рекреационных зон г. Нижнего Новгорода по уровню загрязнения почвы тяжелыми металлами (ТМ) и значениям биоиндикационных показателей березы повислой (Betula pendula Roth). Объектами исследования являлись 4 рекреационные зоны (ООПТ (памятники природы) - «Малиновая гряда» и «Щелоковский хутор», парки - «Дубки» и «Швейцария»). В качестве условно-контрольного биотопа рассматривался лесопарк «Щелоковский хутор», удаленный от источников загрязнения. Превышение нормативных показателей (в кратностях ПДК (ОДК)) по валовому содержанию тяжелых металлов наблюдалось в почвах только для никеля: в парке «Швейцария» - в 1,3 раза, в ООПТ «Малиновая гряда» - в 2,3 раза. Наиболее загрязненными тяжелыми металлами по суммарному показателю загрязнения (Zф) оказались почвы с категорией загрязнения - «умеренно опасные»: в ООПТ «Малиновая гряда» и в парке «Дубки». Биоиндикационные показатели листа B. pendula отклонялись от условной нормы на ряде изученных территорий. Так, качество среды, оцененное по интегральному показателю флуктуирующей асимметрии листа березы на территории ООПТ «Щелоковский хутор» и парка «Дубки», соответствовало 2 баллам (незначительное отклонение от нормы), на территории парка «Швейцария» - 3 баллам (среднее отклонение от нормы), а на ООПТ «Малиновая гряда» - 4 баллам (существенное отклонение от нормы). На двух наиболее загрязненных участках (парк «Дубки» и ООПТ «Малиновая гряда») отмечалось снижение содержания хлорофиллов в листе $B$. pendula относительно контроля (ООПТ «Щелоковский хутор»).

Ключевые слова: г. Нижний Новгород; рекреационная зона; почва; тяжелые металлы; медь; кобальт; никель; свинец; цинк; марганец; кадмий; хром; железо; ртуть; суммарный показатель загрязнения почв тяжелыми металлами; Betula pendula Roth; лист; флуктуирующая асимметрия; хлорофиллы; каротиноиды; биоиндикация. 
Транспортные средства и промышленность (угледобывающая, металлургическая, химическая, энергетическая) являются основными источниками поступления тяжелых металлов в окружающую среду $[1$, c. $1-10 ; 2$, с. 24], в том числе и на урбанизированных территориях. Тяжелые металлы, поступая в почву даже в небольших количествах, способны аккумулироваться и длительно сохраняться в ней, в частности связываясь с компонентами гумуса. Особенно прочно закрепляются на гумусовом барьере элементы-биофилы: медь и свинец [3, с. $284 ; 4$, с. 102]. Так, период полуудаления свинца из почвы составляет 740-5900 лет, а для меди этот период равен 310 1500 лет [5, с. 32-33].

В условиях крупных городов, к которым относится и г. Нижний Новгород, отмечается превышение ПДК для тяжелых металлов не только в промышленных зонах и на придорожных территориях, но и в зонах рекреации (парках, скверах и др.) [6, с. 201], сохранение фитоценозов которых представляет собой важную проблему, поскольку напрямую связано с качеством жизни горожан.

По суммарному загрязнению почвы тяжелыми металлами (свинец, хром, никель, молибден, олово, ванадий, медь, цинк, кобальт, кадмий, ртуть) большая часть территории г. Нижнего Новгорода относится к категории допустимого загрязнения, около $30 \%$ характеризуется умеренно опасным, около 10\% - опасным загрязнением почвенного покрова; на отдельных участках ( $3 \%)$ обнаружено чрезвычайно опасное загрязнение почвы тяжелыми металлами. При этом соотношение почв с разным уровнем загрязнения данными поллютантами в заречных и нагорных районах города существенно различается. В нагорной части г. Нижнего Новгорода преобладают допустимые уровни загрязнения почв, в заречной части - допустимые, а также умеренно опасно загрязненные. Кроме того, присутствуют достаточно большие территории с очень опасным уровнем загрязнения. В нагорной же части города обнаружено больше локальных участков чрезвычайно опасного загрязнения [6, с. 155].

ООПТ (памятники природы) «Малиновая гряда» и «Щелоковский хутор», а также парки «Дубки» и «Швейцария» относятся к важнейшим зонам рекреации жителей г. Нижнего Новгорода. В то же время оценка экологического состояния данных территорий не проводилась.

Целью исследования являлась оценка состояния рекреационных зон г. Нижнего Новгорода по содержанию тяжелых металлов в почве и значениям биоиндикационных показателей листа $B$. pendula.

\section{Материалы и методика исследований}

Объектами исследования являлись почва и листья B. pendula в 4 рекреационных зонах города, расположенных в нагорных районах: ООПТ (памятники природы) - «Малиновая гряда» и «Щелоковский хутор», парки - «Дубки» и «Швейцария».

В целях оценки состояния природных комплексов рекреационных зон г. Нижнего Новгорода проведены экологические исследования на территории двух ООПТ - «Малиновая гряда» и «Щелоковский хутор», а также в двух парках «Дубки» и «Швейцария». В качестве условно-контрольного рассматривался лесопарк «Щелоковский хутор», удаленный от источников загрязнения. «Щелоковский хутор» - это естественный массив широколиственного леса у юго- восточной границы города Нижнего Новгорода [6, с. 101], поэтому валовое содержание тяжелых металлов в почве данной рекреационной зоны было принято за фоновый уровень.

Определение валового содержания тяжелых металлов в почве (медь, кобальт, никель, свинец, цинк, марганец, кадмий, хром, железо, ртуть) было проведено в лаборатории физико-химических методов анализа ЦМС ФГБУ «Верхне-Волжское УГМС» с использованием атомно-абсорбционного спектрофотометра «Квант-2АТ», определение содержания ртути осуществлялось методом атомной абсорбции в холодном паре с помощью «УКР-1 МЦ». Определение $\mathrm{pH}$ проведено с использованием $\mathrm{pH}$-метра «Hanna pH-211».

Качество аналитической работы по определению тяжелых металлов в пробах почвы оценивалось по результатам внешнего (пяти контрольных образцов в пяти повторностях) и внутрилабораторного контроля. Внутрилабораторный контроль состоял из статистического контроля точности и контроля воспроизводимости полученных результатов (РД 52.18.718-2008).

Значения фоновых массовых долей тяжелых металлов использованы для оценки опасности загрязнения почвы комплексом металлов по суммарному показателю загрязнения Zф согласно МУ 2.1.7.73099 [7, с. 10-11] и СанПиН 2.1.7.1287-03 [8, с. 32], который рассчитан по формуле:

$$
Z_{\phi}=\sum_{i=1}^{n} K_{\phi i}-(n-1),
$$

где $n$ - количество определяемых металлов, $K_{\phi i}-$ коэффициент концентрации металла, равный отношению массовой доли $i$-го металла в почве загрязнённой территории к его фоновой массовой доле.

Известно, что тяжелые металлы приводят к снижению уровня содержания фотосинтетических пигментов в листе растений $[9$, с. $179 ; 10$, с. 29]. Содержание хлорофиллов и каротиноидов определяли, объединяя фрагменты 25-30 листьев, собранные с данного дерева, в одну пробу. В каждой рекреационной зоне, таким образом, оценивали содержание фотосинтетических пигментов у 10 деревьев $(\mathrm{n}=10)$. Согласно общепринятой методике, для экстрагирования пигментов использовали 80\% ацетон [11, с. 154-170].

Для оценки флуктуирующей асимметрии листа, являющейся биоиндикационным показателем [12, c. $1489 ; 13$, с. $411 ; 14$, с. $143 ; 15$, с. 117$]$, на каждом участке собирали по 10 листьев с каждого из 10 деревьев $(\mathrm{n}=100)$ березы повислой (Betula pendula Roth). Листья сканировали, в программе Adobe Photoshop Portable измеряли стандартный набор из 5 промеров листа [16, с. 200-210]. Расчет интегрального показателя флуктуирующей асимметрии проводили, используя алгоритм нормированной разности [17, с. 404].

\section{Результаты исследований и их обсуждение}

Превышение нормативных показателей по валовому содержанию тяжелых металлов было отмечено в почвах только для никеля (в кратностях ПДК $($ ОДК)): в парке «Швейцария» в 1,3 раза, в ООПТ «Малиновая гряда» - в 2,3 раза. Превышения нормативных показателей по другим тяжелым металлам в обследованных рекреационных зонах не отмечено. В то же время в почвах изученных рекреационных тер- 
Сидоренко М.В., Юнина В.П., Ерофеева Е.А., Савинов А.Б., Кузнецов М.Д., Новожилов Д.А.

Оценка экологического состояния рекреационных зон г. Нижнего Новгорода..

Общая биология

риторий по сравнению с фоновым уровнем (ООПТ «Щелоковский хутор») в большинстве случаев отмечалось статистически значимое существенное увеличение уровня многих изученных тяжелых металлов, за исключением свинца, ртути и кадмия (табл. 1), что указывает на поступление данных поллютантов в зоны отдыха от близко расположенных автодорог. Следует отметить, что сходная ситуация с загрязнением почвы тяжелыми металлами была описана ранее и в других парках города. Авторы также продемонстрировали превышение нормативов только для отдельных тяжелых металлов и накопление данных поллютантов в почвах рекреационных зон по сравнению с фоновым уровнем [18, с. 191; 19, с. 109].

Наиболее загрязненными тяжелыми металлами по показателю Zф в соответствии с МУ 2.1.7.730-99 оказались почвы с категорией загрязнения - умеренно опасные: в ООПТ «Малиновая гряда» и в парке «Дубки» (табл. 2). В других обследованных рекреационных зонах категория загрязнения почв тяжелыми металлами характеризуется как допустимая.

Величины интегрального показателя флуктуирующей асимметрии статистически значимо не различались на загрязненных и контрольном участках (табл. 3). В то же время на двух наиболее загрязненных участках (парк «Дубки» и ООПТ «Малиновая гряда») отмечалось снижение содержания хлорофиллов в листьях березы относительно контрольного уровня (табл. 3), что характерно для токсического действия тяжелых металлов на фотосинтетический аппарат растений $[20$, с. $683 ; 9$, с. $179 ; 10$, с. 29], способных вызывать деградацию хлорофиллов и нарушать их биосинтез $[21$, с. 33]. Согласно балльной шкале В.М. Захарова с соавторами [16, с. 302], каче- ство среды, оцененное по интегральному показателю флуктуирующей асимметрии листьев березы, на территории ООПТ «Щелоковский хутор» и парка «Дубки» соответствовало 2 баллам (незначительное отклонение от нормы), на территории парка «Швейцария» - 3 баллам (среднее отклонение от нормы), а на ООПТ «Малиновая гряда» - 4 баллам (существенное отклонение от нормы). Нарушение стабильности развития листа и, как следствие этого, возрастание флуктуирующей асимметрии у различных видов растений при воздействии тяжелых металлов описано разными авторами [22, с. $189 ; 23$, с. 471$]$.

Таким образом, нами установлено, что в парке «Дубки» и ООПТ «Малиновая гряда» наблюдается выраженное отклонение состояния окружающей среды от условной нормы как по суммарному показателю $(Z \phi)$ загрязнения почв тяжелыми металлами, так и по биоиндикационным параметрам листа березы повислой (флуктуирующей асимметрии и уровню содержания хлорофиллов а и b в листьях), а на территории парка «Швейцария» отмечается нарушение стабильности развития листьев березы, несмотря на допустимое значение суммарного показателя загрязнения почвы. Возможно, это обусловлено превышением нормативов содержания никеля в почве данного участка или воздействием других антропогенных факторов среды. Источниками поступления тяжелых металлов в почвы данных рекреационных зон является автомобильный транспорт, поскольку указанные зоны, в отличие от условно-контрольной территории (ООПТ «Щелоковский хутор»), граничат с автомобильными дорогами с высокой интенсивностью потока автотранспорта.

таблица 1 - Валовое содержание тяжелых металлов в почвах рекреационных зон г. Нижнего Новгорода

\begin{tabular}{|c|c|c|c|c|c|c|c|c|c|c|}
\hline \multirow{2}{*}{ Рекреационная зона } & \multicolumn{10}{|c|}{ Валовое содержание тяжелых металлов, мг/кг } \\
\hline & $\mathrm{Cu}$ & Co & $\mathrm{Ni}$ & $\mathrm{Pb}$ & $\mathrm{Zn}$ & $\mathrm{Mn}$ & $\mathrm{Cd}$ & $\mathrm{Cr}$ & $\mathrm{Fe}$ & $\mathrm{Hg}$ \\
\hline $\begin{array}{l}\text { ООПТ «Щелоковский } \\
\text { хутор» (контроль, } \\
\text { фоновый уровень) }\end{array}$ & $\begin{array}{l}16,2 \pm \\
\pm 3,1\end{array}$ & $\begin{array}{l}8,2 \pm \\
\pm 1,8\end{array}$ & $\begin{array}{c}23,1 \pm \\
\pm 4,8\end{array}$ & $\begin{array}{l}10,9 \pm \\
\pm 2,1\end{array}$ & $\begin{array}{l}31,0 \pm \\
\pm 6,8\end{array}$ & $\begin{array}{l}678,8 \pm \\
\pm 126,8\end{array}$ & $\begin{array}{l}0,5 \pm \\
\pm 0,1\end{array}$ & $\begin{array}{c}11,1 \pm \\
\pm 2,1\end{array}$ & $\begin{array}{c}1357,0 \pm \\
\pm 255,8\end{array}$ & $\begin{array}{l}0,02 \pm \\
\pm 0,01\end{array}$ \\
\hline $\begin{array}{l}\text { Парк } \\
\text { «Швейцария» }\end{array}$ & $\begin{array}{l}36,7 \pm \\
\pm 6,5^{*}\end{array}$ & $\begin{array}{l}10,5 \pm \\
\pm 2,1\end{array}$ & $\begin{array}{l}101,2 \pm \\
\pm 20,8^{*}\end{array}$ & $\begin{array}{l}11,0 \pm \\
\pm 1,8\end{array}$ & $\begin{array}{c}67,5 \pm \\
\pm 14,8^{*}\end{array}$ & $\begin{array}{l}1355,8 \pm \\
\pm 208,8^{*}\end{array}$ & $\begin{array}{l}0,6 \pm \\
\pm 0,1\end{array}$ & $\begin{array}{l}31,5 \pm \\
\pm 4,8^{*}\end{array}$ & $\begin{array}{l}5540,1 \pm \\
\pm 488,8^{*}\end{array}$ & $\begin{array}{l}0,03 \pm \\
\pm 0,01\end{array}$ \\
\hline Парк «Дубки» & $\begin{array}{l}30,3 \pm \\
\pm 5,1 *\end{array}$ & $\begin{array}{l}8,0 \pm \\
\pm 1,7 \\
\end{array}$ & $\begin{array}{c}28,0 \pm \\
\pm 5,8 \\
\end{array}$ & $\begin{array}{l}10,5 \pm \\
\pm 1,5 \\
\end{array}$ & $\begin{array}{r}72,0 \pm \\
\pm 12,8^{*} \\
\end{array}$ & $\begin{array}{l}853,9 \pm \\
\pm 169,8 \\
\end{array}$ & $\begin{array}{l}0,7 \pm \\
\pm 0,2 \\
\end{array}$ & $\begin{array}{c}18,0 \pm \\
\pm 3,8 \\
\end{array}$ & $\begin{array}{l}2592,2 \pm \\
\pm 302,8^{*} \\
\end{array}$ & $\begin{array}{l}0,04 \pm \\
\pm 0,01 \\
\end{array}$ \\
\hline $\begin{array}{l}\text { ООПТ } \\
\text { «Малиновая гряда» }\end{array}$ & $\begin{array}{l}44,2 \pm \\
\pm 8,1 *\end{array}$ & $\begin{array}{l}14,1 \pm \\
\pm 2,8^{*}\end{array}$ & $\begin{array}{l}202,1 \pm \\
\pm 28,9 *\end{array}$ & $\begin{array}{l}10,8 \pm \\
\pm 1,6\end{array}$ & $\begin{array}{l}73,1 \pm \\
\pm 13,9 *\end{array}$ & $\begin{array}{l}1428,1 \pm \\
\pm 285,0 *\end{array}$ & $\begin{array}{l}0,5 \pm \\
\pm 0,1\end{array}$ & $\begin{array}{c}58,2 \pm \\
\pm 12,8^{*}\end{array}$ & $\begin{array}{c}7106,5 \pm \\
\pm 1022,5^{*}\end{array}$ & $\begin{array}{l}0,04 \pm \\
\pm 0,01\end{array}$ \\
\hline
\end{tabular}

Примечание. *-статистически значимое отличие от контрольного уровня (p < 0,05) (среднее \pm ошибка).

Таблица 2 - Показатели состояния почв рекреационных зон г. Нижнего Новгорода

\begin{tabular}{|c|l|c|c|c|c|}
\hline $\begin{array}{c}\text { № } \\
\text { п/п }\end{array}$ & \multicolumn{1}{|c|}{ Место отбора пробы } & $\begin{array}{c}\text { Механический состав } \\
\text { почв }\end{array}$ & $\mathrm{pH}$ & $\mathrm{Zф}$ & $\begin{array}{c}\text { Категория } \\
\text { загрязнения почв }\end{array}$ \\
\hline 1 & ООПТ «Щелоковский хутор» (контроль) & средний суглинок & 7,14 & 1,5 & допустимая \\
\hline 2 & Парк «Швейцария» & тяжелый суглинок & 6,89 & 10,6 & допустимая \\
\hline 3 & Парк «Дубки» & тяжелый суглинок & 6,24 & 16,7 & умеренно опасная \\
\hline 4 & ООПТ «Малиновая гряда» & средний суглинок & 6,07 & 18,8 & умеренно опасная \\
\hline
\end{tabular}

таблица 3 - Показатели флуктуирующей асимметрии и содержания фотосинтетических пигментов в листьях B. pendula на территориях рекреационных зон г. Нижнего Новгорода

\begin{tabular}{|l|c|c|c|c|}
\hline \multicolumn{1}{|c|}{ Рекреационная зона } & $\begin{array}{c}\text { Хлорофилл а, мг/г } \\
\text { сырой массы листа }\end{array}$ & $\begin{array}{c}\text { Хлорофилл b, мг/г } \\
\text { сырой массы листа }\end{array}$ & $\begin{array}{c}\text { Каротиноиды, мг/г } \\
\text { сырой массы листа }\end{array}$ & $\begin{array}{c}\text { Флуктуирующая } \\
\text { асимметрия листа }\end{array}$ \\
\hline $\begin{array}{l}\text { ООПТ «Щелоковский } \\
\text { хутор» (контроль) }\end{array}$ & $1,959 \pm 0,081$ & $1,024 \pm 0,057$ & $0,301 \pm 0,012$ & $0,0443 \pm 0,0019$ \\
\hline Парк «Швейцария & $1,743 \pm 0,072$ & $0,756 \pm 0,042$ & $0,300 \pm 0,009$ & $0,0490 \pm 0,0022$ \\
\hline Парк «Дубки» & $1,570 \pm 0,053^{*}$ & $0,623 \pm 0,040^{*}$ & $0,297 \pm 0,004$ & $0,0415 \pm 0,0018$ \\
\hline ООПТ «Малиновая гряда» & $1,712 \pm 0,022$ & $0,669 \pm 0,023^{*}$ & $0,325 \pm 0,040$ & $0,0500 \pm 0,024$ \\
\hline
\end{tabular}

Примечание. *-статистически значимое отличие от контрольного уровня (p < 0,05) (среднее \pm ошибка). 


\section{Выводы}

1. На территории условного контрольного участка (ООПТ «Щелоковский хутор») фоновое содержание изученных тяжелых металлов в почве и суммарный показатель загрязнения почвы тяжелыми металлами не превышали установленных нормативов. В парках «Дубки» и «Швейцария», а также ООПТ «Малиновая гряда» наблюдалось выраженное отклонение состояния окружающей среды от условной нормы (фонового уровня) по валовому содержанию тяжелых металлов в почвенном покрове и суммарному показателю загрязнения почв тяжелыми металлами. В то же время в данных рекреационных зонах только валовое содержание никеля в почве превышало установленные нормативы.

2. В парке «Дубки» и ООПТ «Малиновая гряда» выявлено снижение уровня хлорофиллов а и $\mathrm{b}$ в листьях B. pendula по сравнению с контрольными значениями, что могло быть обусловлено полиметаллическим загрязнением почвенного покрова.

3. Качество среды, оцененное по интегральному показателю флуктуирующей асимметрии листа $B$. pendula на территории ООПТ «Щелоковский хутор» и парка «Дубки», соответствовало 2 баллам (незначительное отклонение от нормы), на территории парка «Швейцария» - 3 баллам (среднее отклонение от нормы), а на ООПТ «Малиновая гряда» - 4 баллам (существенное отклонение от нормы), что указывает на высокую чувствительность стабильности развития листа B. pendula к превышению фоновых уровней изученных тяжелых металлов в почве даже в том случае, когда превышение фона остается в границах нормативов.

\section{Список литературы:}

1. Титов А.Ф., Казнина Н.М., Таланова В.В. Тяжелые металлы и растения. Петрозаводск: Карельский научный центр РАН, 2014. 194 с.

2. Su C., Jiang L.Q., Zhang W.J. A review on heavy metal contamination in the soil worldwide: Situation, impact and remediation techniques // Environmental Skeptics and Critics. 2014. Vol. 3, № 2. P. 24-38.

3. Алексеенко В.А. Экологическая геохимия. М.: Логос, 2000. $627 \mathrm{c}$.

4. Водяницкий Ю.Н. Тяжелые металлы и металлоиды в почвах. М.: ГНУ «Почвенный институт им. В.В. Докучаева РАСХН», 2008. 164 с.

5. Кабата-Пендиас А., Пендиас Х. Микроэлементы в почвах и растениях. М.: Мир, 1989. 440 с.

6. Гелашвили Д.Б., Копосов Е.В., Лаптев Л.А. Экология Нижнего Новгорода. Нижний Новгород: Деловая Полиграфия, 2007. 256 с.

7. МУ 2.1.7.730-99 Гигиеническая оценка качества почвы населённых мест. М.: Минздрав России. 1999. $45 \mathrm{c}$.

8. СанПиН 2.1.7.1287-03 Санитарно-эпидемиологические правила и нормативы. Санитарно-эпидемиологические требования к качеству почвы. М.: Федеральный центр гигиены и эпидемиологии Роспотребнадзора, 2005. 38 с.

9. Gupta A.K., Sinha S. Antioxidant response in sesame plants grown on industrially contaminated soil: effect on oil yield and tolerance to lipid peroxidation // Bioresource Technology. 2009. Vol. 100, № 1. P. 179-185.
10. El-Khatib A.A., Hegazy A.K, Abo-El-Kassem A.M. Bioaccumulation potential and physiological responses of aquatic macrophytes to $\mathrm{Pb}$ pollution // International Journal of Phytoremediation. 2014. Vol. 16, № 1, P. 29-45.

11. Шлык А.А. Определение хлорофиллов и каротиноидов в экстрактах зеленых листьев // Биохимические методы в физиологии растений. М.: Наука, 1971. C. $154-170$.

12. Kozlov M.V., Wilsey B.J., Koricheva J., Haukioja E. Fluctuation asymmetry of birch leaves increases under pollution impact // Journal of Applied Ecology. 1996. Vol. 33. P. 1489-1495.

13. Hao Z., Xiangrong W. Leaf developmental stability of Platanus acerifolia under urban environmental stress and its implication as an environmental indicator // Frontiers of Biology in China. 2006. Vol. 4. P. 411-417.

14. Baranov S.G. Littleleaf linden Tillia cordata (Mill.): only some bilateral traits indicate chemical pollution induced by chemical plant // Advances in Biological Research. 2014. Vol. 8, № 4. P. 143-148.

15. Shadrina E.G., Vol'pert Ya.L. Developmental instability of the organism as a result of pessimization of environment under anthropogenic transformation of natural landscapes // Russian Journal of Developmental Biology. 2014. Vol. 45, № 3. P. 117-126.

16. Захаров В.М., Чубинишвили А.Т., Дмитриев С.Г., Баранов А.С. Здоровье среды: Практика оценки. М.: Центр экологической политики России, 2000. 318 с.

17. Захаров В.М., Жданова Н.П., Кирик Е.Ф. и др. Онтогенез и популяция: оценка стабильности развития в природных популяциях // Онтогенез. 2001. Т. 32, № 6. С. 404-421.

18. Савинов А.Б., Курганова Л.Н., Шекунов Ю.И. Интенсивность перекисного окисления липидов у Taraxacum officinale Wigg. и Vicia cracca L. в биотопах с разным уровнем загрязнения почв тяжелыми металлами // Экология. 2007. № 3. С. 191-197.

19. Дабахов М.В., Чеснокова Е.В. Тяжелые металлы в почвах парков заречной части Нижнего Новгорода // Вестник Нижегородского университета им. Н.И. Лобачевского. 2010. № 2 (1). С. 109-116.

20. Pereira L.B., de Mazzanti C.M., Gonçalves J.F., Cargnelutti D., Tabaldi L.A., Becker A.G., Calgaroto N.S., Farias J.G., Battisti V., Bohrer D., Nicoloso F.T., Morsch V.M., Schetinger M.R.C. Aluminum-induced oxidative stress in cucumber // Plant Physiology and Biochemistry. 2010. Vol. 48. P. 683-689.

21. Таланова В.В., Титов А.Ф., Боева Н.П. Влияние свинца и кадмия на проростки ячменя // Физиология и биохимия культурных растений. 2001. Т. 33, № 1. С. 33-37.

22. Mal T.K., Uveges J.L., Turk K.W. Fluctuating asymmetry as an ecological indicator of heavy metal stress in Lythrum salicaria // Ecological Indicators. 2002. Vol. 1. P. 189-195.

23. Tan-Kristanto A., Hoffmann A., Woods R., Batterham P., Cobbett C., Sinclair C. Translational asymmetry as a sensitive indicator of cadmium stress in plants: a laboratory test with wild-type and mutant Arabidopsis thaliana // New Phytologist. 2003. Vol. 159. P. 471-477. 


\title{
ECOLOGICAL STATE ASSESSMENT OF RECREATIONAL AREAS IN NIZHNY NOVGOROD ON HEAVY METAL SOIL POLLUTION AND BIOINDICATION INDICATORS OF BETULA PENDULA ROTH LEAVES
}

(C) 2020

Sidorenko Mikhail Vladimirovich, candidate of biological sciences, associate professor of Ecology Department

Yunina Valentina Petrovna, senior lecturer of Ecology Department

Erofeeva Elena Aleksandrovna, doctor of biological sciences, associate professor of Ecology Department

Savinov Aleksandr Borisovich, candidate of biological sciences, associate professor of Ecology Department

Kuznetsov Maksim Dmitrievich, postgraduate student of Ecology Department

Novozhilov Denis Alekseevich, postgraduate student of Ecology Department

National Research Lobachevsky State University of Nizhny Novgorod (Nizhny Novgorod, Russian Federation)

Abstract. In this paper the ecological state of recreational areas in Nizhny Novgorod was assessed by the level of soil contamination with heavy metals (HM) and the values of bioindication indicators of the birch (Betula pendula Roth). The objects of the study were 4 recreational areas. The forest park «Shelokovsky Farm» located far from pollution sources was chosen as a control site. The excess of normative indicators (in multiplicities of normative indicators) on gross content of HM was observed in soils only for nickel: in the park «Switzerland» in 1,3 times, in «Raspberry Ridge» - in 2,3 times. The soils with the pollution category «moderately dangerous» were the most polluted by HM according to the total indicator of pollution: in the protected area «Crimson Ridge» and in the park «Oaks». Bioindication indicators of a birch leaf deviated from the conventional norm in a number of studied areas. The quality of the environment, estimated by fluctuating asymmetry of birch leaves in «Shelokovsky Farm» and the park «Oaks», correspond to 2 points (a slight deviation from the norm), in the Park «Switzerland» - to 3 points (the average deviation from the norm), and in «Crimson Ridge» - to 4 points (a significant deviation from the norm). In the two most contaminated sites («Oaks» and «Crimson Ridge»), a decrease of chlorophyll content in birch leaves relative to the control («Shelokovsky Farm») was observed.

Keywords: Nizhny Novgorod; recreational zone; soil; heavy metals; copper; cobalt; nickel; lead; zinc; manganese; cadmium; chromium; iron; mercury; total indicator of soil contamination with heavy metals; Betula pendula Roth; leaf; fluctuating asymmetry; chlorophylls; carotenoids; bioindication.

$* * *$

УДК 582.29

DOI 10.24411/2309-4370-2020-11115

Статья поступила в редакцию 15.01.2020

\section{ЭКОЛОГИЯ И РАСПРОСТРАНЕНИЕ РЕДКИХ ВИДОВ ЛИШАЙНИКОВ ЧУВАШСКОГО ПРИСУРЬЯ}

(C) 2020

\author{
Синичкин Евгений Аркадьевич, научный сотрудник \\ Чебоксарский филиал Главного ботанического сада им. Н.В. Цицина РАН \\ (2. Чебоксары, Российская Федераџия)
}

Богданов Геннадий Алексеевич, старший научный сотрудник

Государственный природный заповедник «Большая Кокшага» (г. Йошкар-Ола, Российская Федеращия)

Димитриев Александр Вениаминович, кандидат биологических наук, директор

Чебоксарский филиал Главного ботанического сада им. Н.В. Цицина РАН

(2. Чебоксары, Российская Федераџия)

Аннотаиия. В статье приводятся данные о 20 новых и редких видах лишайников, обнаруженных на тер-
ритории Чувашского Присурья. 10 видов являются новыми для Чувашской Республики, 5 видов - новые для
Приволжской возвышенности. Выявленные виды лишайников являются индикаторами старовозрастных, не-
нарушенных и малонарушенных лесов, которые сохранились на особо охраняемых природных территориях.
На территории Национального парка «Чаваш вармане» отмечено 18 редких видов, в Государственном при-
родном заповеднике «Присурский» - 8 видов. Для каждого вида указываются географические координаты,
особенности распространения в соседних регионах, эколого-субстратная и фитоценотическая приурочен-
ность, возрастное состояние. Уточнены сведения по экологии и распространению редких видов лишайников.
18 видов лишайников (Bryoria nadvornikiana, Br. trichodes, Cetrelia olivetorum, Cresponea chloroconia, Evernia
divaricata, Heterodermia speciosa, Leptogium cyanescens, L. saturninum, Nephroma parile, Scytinium subtile,
Sc. teretiusculum, Sc. tenuissimum, Usnea dasopoga, Us. florida, Us. subfloridana, Ramalina thrausta, R. sinensis,
Хanthoтепdoza ulophyllodes) предложены в новое издание Красной книги Чувашской Республики со статусом
III - редкие виды. 2 вида лишайников (Cetraria ericetorum, Lobaria риlтопаria) отнесены к категории II - уяз-
вимые виды, сокращающиеся в численности.
Ключевые слова: лишайники; лихенофлора; редкие виды; растительные сообщества; лес; сосновые леса;
липовые леса; осиновые леса; березовые леса; ареал; Чувашское Присурье; Государственный природный за-
поведник «Присурский»; Национальный парк «Чаваш вармане»; Алатырский район; Ибресинский район;
особо охраняемая природная территория; Красная книга; Чувашская Республика. 